\title{
A review of the latest USPSTF recommendations
}

\author{
The Task Force has expanded the age range for screening \\ for hepatitis $\mathrm{C}$ virus infection in adolescents and adults, \\ and now endorses behavioral counseling for all adults \\ with any CVD risk factors.
}

$\mathrm{S}$ ince the last Practice Alert update on recommendations made by the US Preventive Services Task Force, ${ }^{1}$ the Task Force has completed work on 12 topics (TABLE 1). ${ }^{2-17}$ Five of these topics have been discussed in JFP audio recordings, and the links are provided in TABLE 1.

This latest Task Force endeavor resulted in 18 recommendations (TABLE 2), all of which reaffirm previous recommendations on these topics and expand the scope of 2 . There were 2 " $\mathrm{A}$ " recommendations, 6 " $\mathrm{B}$ " recommendations, 2 " $\mathrm{D}$ " recommendations, and 8 " $\mathrm{I}$ " statements, indicating that there was insufficient evidence to assess effectiveness or harms. The willingness to make "I" statements when there is little or no evidence on the intervention being assessed distinguishes the USPSTF from other clinical guideline committees.

\section{Screening for carotid artery stenosis}

One of the " $\mathrm{D}$ " recommendations this past year reaffirms the prior recommendation against screening for carotid artery stenosis in asymptomatic adults-ie, those without a history of transient ischemic attack, stroke, or neurologic signs or symptoms that might be caused by carotid artery stenosis. ${ }^{2}$ The screening tests the Task Force researched included carotid duplex ultrasonography (DUS), magnetic resonance angiography, and computed tomography angiography. The Task Force did not look at the value of auscultation for carotid bruits because it has been proven to be inac- curate and they do not consider it to be a useful screening tool.

The Task Force based its " $\mathrm{D}$ " recommendation on a lack of evidence for any benefit in detecting asymptomatic carotid artery stenosis, and on evidence that screening can lead to harms through false-positive tests and potential complications from carotid endarterectomy and carotid artery angioplasty and stenting. In its clinical considerations, the Task Force emphasized the primary prevention of atherosclerotic disease by focusing on the following actions:

- screening for high blood pressure in adults

- encouraging tobacco smoking cessation in adults

- promoting a healthy diet and physical activity in adults with cardiovascular risk factors

- recommending aspirin use to prevent cardiovascular disease and colorectal cancer

- advising statin use for the primary prevention of cardiovascular disease in adults ages 45 to 75 years who have 1 or more risk factors (hyperlipidemia, diabetes, hypertension, smoking) and those with a 10 -year risk of a cardiovascular event of $10 \%$ or greater.

This " $\mathrm{D}$ " recommendation differs from recommendations made by other professional organizations, some of which recommend test-
Doug Campos-Outcalt, MD, MPA

University of Arizona, Phoenix

Ddougco@email.arizona.edu

Dr. Campos-Outcalt is a member of the US Community Preventive Services Task Force.

doi: $10.12788 / \mathrm{jp} .0184$ 


\section{TABLE 1}

\section{Topics reviewed by the USPSTF over the past 12 months}

\begin{tabular}{|c|c|c|c|}
\hline Topic & Date & Outcome (see TABLE 2) & Additional JFP coverage \\
\hline $\begin{array}{l}\text { Screening for asymptomatic } \\
\text { carotid artery stenosis }{ }^{2}\end{array}$ & $2 / 2021$ & Reaffirms previous recommendation & \\
\hline $\begin{array}{l}\text { Interventions for tobacco } \\
\text { smoking cessation in adults, } \\
\text { including pregnant women }\end{array}$ & $1 / 2021$ & Reaffirms previous recommendation & \\
\hline $\begin{array}{l}\text { Screening for hepatitis B virus } \\
\text { infection in adolescents and } \\
\text { adults }^{5,6}\end{array}$ & $12 / 2020$ & Reaffirms previous recommendation & \\
\hline $\begin{array}{l}\text { Screening for hepatitis } C \text { virus } \\
\text { infection in adolescents and } \\
\text { adults }^{7}\end{array}$ & $3 / 2020$ & $\begin{array}{l}\text { Reaffirms previous } \\
\text { recommendation; expands age for } \\
\text { screening to all adults } 18-79 \text { years }\end{array}$ & $\begin{array}{l}\text { 5/2020 podcast } \\
\text { https://bit.ly/3tt064Q }\end{array}$ \\
\hline $\begin{array}{l}\text { Screening for bacterial vaginosis } \\
\text { in pregnant women to prevent } \\
\text { preterm delivery }{ }^{8}\end{array}$ & $4 / 2020$ & Reaffirms previous recommendation & \\
\hline $\begin{array}{l}\text { Behavioral counseling } \\
\text { interventions for healthy diet } \\
\text { and physical activity to prevent } \\
\text { cardiovascular disease in adults } \\
\text { with cardiovascular risk factors }{ }^{9,10}\end{array}$ & $11 / 2020$ & $\begin{array}{l}\text { Expands previous recommendation } \\
\text { to all with CVD risk factors, not just } \\
\text { obese and overweight individuals }\end{array}$ & \\
\hline $\begin{array}{l}\text { Screening for high blood } \\
\text { pressure in children and } \\
\text { adolescents }^{11}\end{array}$ & $11 / 2020$ & Reaffirms previous recommendation & \\
\hline $\begin{array}{l}\text { Interventions to prevent and } \\
\text { stop tobacco use in children and } \\
\text { adolescents }^{12}\end{array}$ & $4 / 2020$ & $\begin{array}{l}\text { Reaffirms previous } \\
\text { recommendation on prevention of } \\
\text { tobacco use; adds an "I" statement } \\
\text { for tobacco cessation in children } \\
\text { and adolescents }\end{array}$ & $\begin{array}{l}\text { 9/2020 podcast } \\
\text { https://bit.ly/33hZx3h }\end{array}$ \\
\hline $\begin{array}{l}\text { Screening for cognitive } \\
\text { impairment in older adults }{ }^{13}\end{array}$ & $2 / 2020$ & $\begin{array}{l}\text { Reaffirms previous } \\
\text { recommendation }\end{array}$ & $\begin{array}{l}\text { 4/2020 podcast } \\
\text { https://bit.ly/3eiEYtY }\end{array}$ \\
\hline $\begin{array}{l}\text { Interventions for illicit drug use } \\
\text { in children, adolescents, and } \\
\text { young adults }{ }^{14}\end{array}$ & $5 / 2020$ & $\begin{array}{l}\text { Reaffirms previous } \\
\text { recommendation; expands age to } \\
\text { include } 18-25 \text { years }\end{array}$ & \multirow{2}{*}{$\begin{array}{l}\text { 9/2020 podcast } \\
\text { https://bit.ly/33hZx3h }\end{array}$} \\
\hline $\begin{array}{l}\text { Screening for unhealthy drug } \\
\text { use }^{15}\end{array}$ & $6 / 2020$ & $\begin{array}{l}\text { Changes "I" statement to a "B" } \\
\text { recommendation for adults } \geq 18 \text {; } \\
\text { reaffirms "I" statement for } \\
<18 \text { years }\end{array}$ & \\
\hline $\begin{array}{l}\text { Behavioral counseling for } \\
\text { sexually transmitted infections }{ }^{16}\end{array}$ & $8 / 2020$ & $\begin{array}{l}\text { Reaffirms previous } \\
\text { recommendation; expands } \\
\text { counseling options available }\end{array}$ & 12/2020 Practice Alert ${ }^{17}$ \\
\hline
\end{tabular}

CVD, cardiovascular disease; USPSTF, US Preventive Services Task Force.

ing with DUS for asymptomatic patients with a carotid bruit, and others that recommend DUS screening in patients with multiple risk factors for stroke and in those with known peripheral artery disease or other cardiovascular disease. ${ }^{18,19}$

\section{Smoking cessation in adults}

Smoking tobacco is the leading preventable cause of death in the United States, caus- ing about 480,000 deaths annually. ${ }^{3}$ Smoking during pregnancy increases the risk of complications including miscarriage, congenital anomalies, stillbirth, fetal growth restriction, preterm birth, and placental abruption.

The Task Force published recommendations earlier this year advising all clinicians to ask all adult patients about tobacco use; and, for those who smoke, to provide (or refer them 


\section{USPSTF recommendations made in the past 12 months}

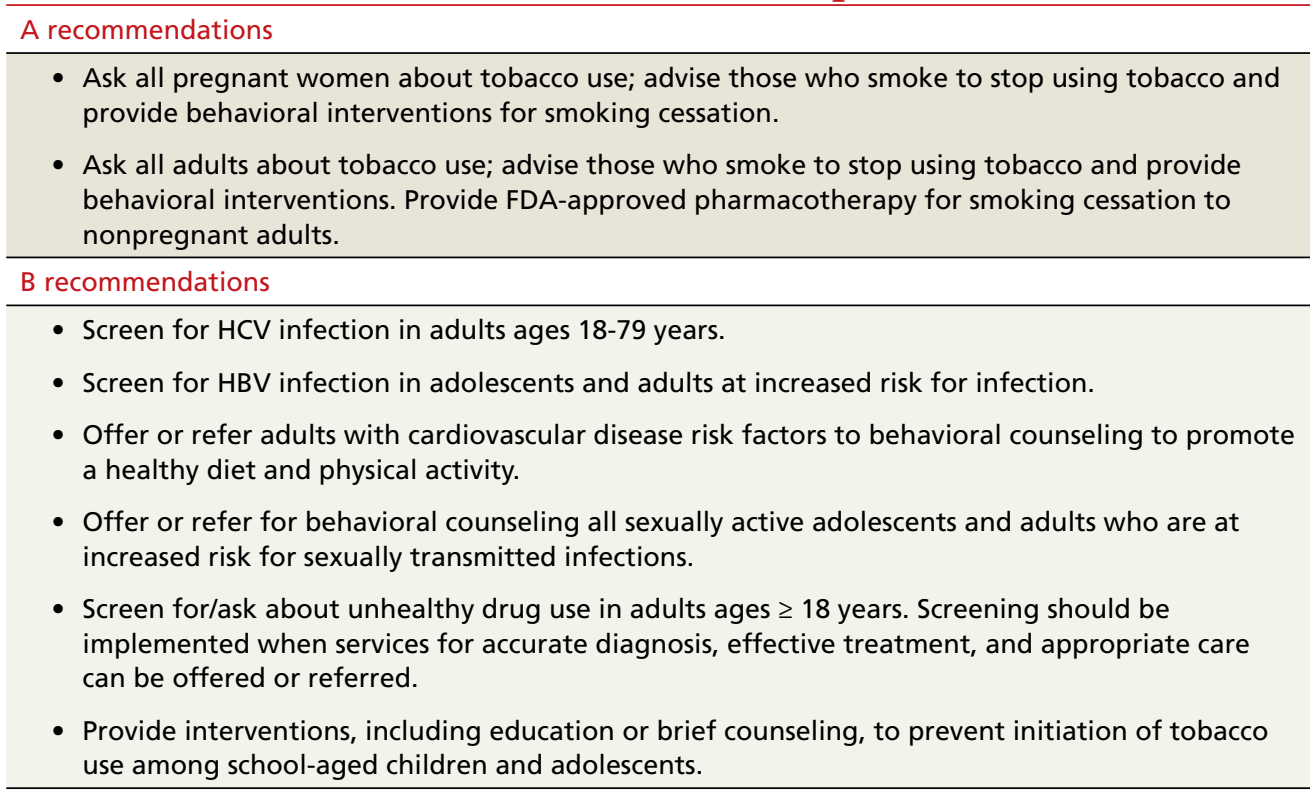

D recommendations

- Do not screen for asymptomatic carotid artery stenosis in the general adult population.

- Do not screen for BV in pregnant women who are not at increased risk for preterm delivery.

I statements
- Screening for cognitive impairment in older adults
- Pharmacotherapy interventions for tobacco cessation in pregnant women
- Use of electronic cigarettes for tobacco cessation in adults, including pregnant women
- Screening for high blood pressure in children and adolescents
- Screening for unhealthy drug use in adolescents
- Primary care-based behavioral counseling interventions to prevent illicit drug use (including
- nonmedical use of prescription drugs) in children, adolescents, and young adults
- Scare-feasible interventions for the cessation of tobacco use among school-aged children
- Screening for BV in pregnant women who are at increased risk for preterm delivery

$B V$, bacterial vaginosis; FDA, Food and Drug Administration; $\mathrm{HBV}$, hepatitis $B$ virus; $\mathrm{HCV}$, hepatitis $\mathrm{C}$ virus.

Grade A: There is high certainty that the net benefit is substantial.

Grade B: There is high certainty that the net benefit is moderate, or there is moderate certainty that the net benefit is moderate to substantial.

Grade C: There is at least moderate certainty that the net benefit is small. Offer selectively.

Grade D: There is moderate or high certainty that the service has no net benefit or that the harms outweigh the benefits.

I statement: Current evidence is insufficient to assess the balance of benefits and harms of the service.

to) smoking cessation behavioral therapy. The Task Force also recommends prescribing pharmacotherapy approved by the Food and Drug Administration (FDA) for smoking cessation for nonpregnant adults. (There is a lack of information to assess the harms and benefits of smoking cessation pharmacotherapy during pregnancy.)
FDA-approved medications for treating tobacco smoking dependence are nicotine replacement therapy (NRT), bupropion hydrochloride, and varenicline. ${ }^{3}$ NRT is available in transdermal patches, lozenges, gum, inhalers, and nasal sprays.

In addition, the Task Force indicates that
The Task Force recommends prescribing pharmacotherapy approved by the FDA for smoking cessation for nonpregnant adults. 


\section{$>$}

\section{Screening} individuals at high risk for HBV infection is important because nearly two-thirds of those infected are unaware of their condition. there is insufficient evidence to assess the benefits and harms of e-cigarettes when used as a method of achieving smoking cessation: "Few randomized trials have evaluated the effectiveness of e-cigarettes to increase tobacco smoking cessation in nonpregnant adults, and no trials have evaluated e-cigarettes for tobacco smoking cessation in pregnant persons." $^{4}$

\section{Hepatitis B infection screening}

The Task Force reaffirmed a previous recommendation to screen for hepatitis $B$ virus (HBV) infection only in adults who are at high risk, ${ }^{5}$ rather than universal screening that it recommends for hepatitis $\mathrm{C}$ virus infection (HCV). ${ }^{7}$ (See: https://bit.ly/3tt064Q). The Task Force has a separate recommendation to screen all pregnant women for hepatitis B at the first prenatal visit. ${ }^{6}$

Those at high risk for hepatitis $\mathrm{B}$ who should be screened include individuals born in countries or regions of the world with a hepatitis B surface antigen (HBsAg) prevalence $\geq 2 \%$ and individuals born in the United States who have not received HBV vaccine and whose parents were born in regions with an HBsAg prevalence $\geq 8 \% .^{5}$ (A table listing countries with HBsAg $\geq 8 \%$-as well as those in lower prevalence categories-is included with the recommendation. ${ }^{5}$ )

HBV screening should also be offered to other high-risk groups that have a prevalence of positive $\mathrm{HBsAg} \geq 2 \%$ : those who have injected drugs in the past or are currently injecting drugs; men who have sex with men; individuals with HIV; and sex partners, needle-sharing contacts, and household contacts of people known to be HBsAg positive. ${ }^{5}$

It is estimated that $>860,000$ people in the United States have chronic HBV infection and that close to two-thirds of them are unaware of their infection..$^{5}$ The screening test for HBV is highly accurate; sensitivity and specificity are both $>98 \%{ }^{5}$ While there is no direct evidence that screening, detecting, and treating asymptomatic $\mathrm{HBV}$ infection reduces morbidity and mortality, the Task Force felt that the evidence for improvement in multiple outcomes in those with HBV when treated with antiviral regimens was sufficient to support the recommendation.

\section{Screening for bacterial vaginosis in pregnancy}

While bacterial vaginosis (BV) is associated with a two-fold risk of preterm delivery, treating BV during pregnancy does not seem to reduce this risk, indicating that some other variable is involved. ${ }^{8}$ In addition, studies that looked at screening for, and treatment of, asymptomatic BV in pregnant women at high risk for preterm delivery (defined primarily as those with a previous preterm delivery) have shown inconsistent results. There is the potential for harm in treating BV in pregnancy, chiefly involving gastrointestinal upset caused by metronidazole or clindamycin.

Given that there are no benefits-and some harms-resulting from treatment, the Task Force recommends against screening for BV in non-high-risk pregnant women. A lack of sufficient information to assess any potential benefits to screening in high-risk pregnancies led the Task Force to an "I" statement on this question. $^{8}$

\section{Behavioral counseling on healthy diet, exercise for adults with CV risks}

Cardiovascular disease (CVD) remains the number one cause of death in the United States. The major risk factors for CVD, which can be modified, are high blood pressure, hyperlipidemia, diabetes, smoking, obesity or overweight, and lack of physical activity.

The Task Force has previously recommended intensive behavioral interventions to improve nutrition and physical activity in those who are overweight/obese and in those with abnormal blood glucose levels, ${ }^{9}$ and has addressed smoking prevention and cessation. ${ }^{4}$ This new recommendation applies to those with other CVD risks such as high blood pressure and/or hyperlipidemia and those with an estimated 10-year CVD risk of $\geq 7.5 \%$. $^{10}$

Behavioral interventions included in the Task Force analysis employed a median of 12 contacts and an estimated 6 hours of contact time over 6 to 18 months. ${ }^{10}$ Most interventions involved motivational interviewing and instruction on behavioral change methods. These interventions can be provided by primary care clinicians, as well as a wide range of other trained professionals. The Affordable Care Act dictates that all " $\mathrm{A}$ " and " $\mathrm{B}$ " recom- 
mendations must be provided by commercial health plans at no out-of-pocket expense for the patient.

Nutritional advice should include reductions in saturated fats, salt, and sugars and increases in fruits, vegetables, and whole grains. The Mediterranean diet and the Dietary Approaches to Stop Hypertension (DASH) diet are often recommended. ${ }^{10}$ Physical activity counseling should advocate for 90 to $180 \mathrm{~min}$ utes per week of moderate to vigorous activity.

This new recommendation, along with the previous ones pertaining to behavioral interventions for lifestyle changes, make it clear that intensive interventions are needed to achieve meaningful change. Simple advice from a clinician will have little to no effect.

\section{Task Force reviews evidence on HTN, smoking cessation in young people}

In 2020 the Task Force completed reviews of evidence relevant to screening for high blood pressure $^{11}$ and intervening for tobacco prevention and cessation in children and adolescents. ${ }^{12}$ The Task Force concluded that the evidence is insufficient to make a judgment on screening for high blood pressure and for providing smoking cessation interventions. It did, however, reaffirm a previous recommendation to provide interventions to children and adolescents to prevent tobacco and e-cigarette use.

The 2 "I" statements are in disagreement with recommendations of other professional organizations. The American Academy of Pediatrics (AAP) and the American Heart Association recommend routine screening for high blood pressure starting at age 3 years. And the AAP recommends screening teenagers for tobacco use and offering tobacco dependence treatment, referral, or both (including pharmacotherapy) when indicated. E-cigarettes are not recommended as a treatment for tobacco dependence. ${ }^{20}$

The difference between the methods used by the Task Force and other guidelineproducing organizations becomes apparent when it comes to recommendations pertaining to children and adolescents, for whom longterm outcome-oriented studies on prevention issues are rare. The Task Force is unwilling to make recommendations when evidence does not exist. The AAP often makes recommendations based on expert opinion consensus in such situations. One notable part of each Task Force recommendation statement is a discussion of what other organizations recommend on the same topic so that these differences can be openly described.

\section{Better Task Force funding could expand topic coverage}

It is worth revisiting 2 issues that were pointed out in last year's USPSTF summary in this column. ${ }^{1}$ First, the Task Force methods are robust and evidence based, and recommendations therefore are rarely changed once they are made at an "A", "B", or "D" level. Second, Task Force resources are finite, and thus, the group is currently unable to update previous recommendations with greater frequency or to consider many new topics. In the past 2 years, the Task Force has developed recommendations on only 2 completely new topics. Hopefully, its budget can be expanded so that new topics can be added in the future.

JFP

\footnotetext{
References

1. Campos-Outcalt D. USPSTF roundup. J Fam Pract. 2020;69 201-204.

2. USPSTF. Screening for asymptomatic carotid artery stenosis. Accessed April 30, 2021. https://uspreventiveservicestaskforce. org/uspstf/recommendation/carotid-artery-stenosis-screening

3. USPSTF. Interventions for tobacco smoking cessation in adults, including pregnant persons. Accessed April 30, 2021. www. uspreventiveservicestaskforce.org/uspstf/recommendation/ tobacco-use-in-adults-and-pregnant-women-counseling-andinterventions

4. USPSTF. Interventions for tobacco smoking cessation in adults, including pregnant persons. JAMA. 2021;325:265-279.

5. USPSTF. Screening for Hepatitis $B$ virus infection in adolescents and adults. Accessed April 30, 2021. https:// uspreventiveservicestaskforce.org/uspstf/recommendation/ hepatitis-b-virus-infection-screening

6. USPSTF. Hepatitis B virus infection in pregnant women: screening. Accessed April 30, 2021. https://uspreventiveservicestaskforce. org/uspstf/recommendation/hepatitis-b-virus-infection-inpregnant-women-screening.

7. USPSTF. Hepatitis $\mathrm{C}$ virus infection in adolescents and adults: screening. Accessed April 30, 2021. https:// uspreventiveservicestaskforce.org/uspstf/recommendation/ hepatitis-c-screening

8. USPSTF; Owens DK, Davidson KW, Krisk AH, et al. Screening for bacterial vaginosis in pregnant persons to prevent preterm delivery: US Preventive Services Task Force recommendation statement JAMA. 2020;323:1286-1292.

9. Behavioral counseling to promote a healthful diet and physical activity for cardiovascular disease prevention in adults with cardiovascular risk factors: U.S. Preventive Services Task Force recommendation statement. Ann Intern Med. 2014;161:587-593.

10. USPSTF. Behavioral counseling interventions to promote a healthy and physical activity for cardiovascular disease prevention in adults with cardiovascular risk factors: US Preventive Services Task Force recommendation statement. JAMA. 2020;324:2069-2075.
}

Screening for asymptomatic carotid artery stenosis is discouraged due to a lack of evidence for benefit in detection, and on evidence that false-positives lead to harm from procedures such as endarterectomy. 
11. USPSTF. High blood pressure in children and adolescents: screening. Accessed April 30, 2021. https://uspreventiveservicestaskforce. org/uspstf/recommendation/blood-pressure-in-children-andadolescents-hypertension-screening

12. USPSTF. Prevention and cessation of tobacco use in children and adolescents: primary care interventions. Accessed April 30, 2021. https://uspreventiveservicestaskforce.org/uspstf/ recommendation/tobacco-and-nicotine-use-prevention-inchildren-and-adolescents-primary-care-interventions

13. USPSTF. Cognitive impairment in older adults: screening. Accessed March 26, 2021. https://uspreventiveservicestaskforce. org/uspstf/recommendation/cognitive-impairment-in-olderadults-screening

14. USPSTF. Illicit drug use in children, adolescents, and young adults: primary care-based interventions. Accessed April 30, 2021. https:// uspreventiveservicestaskforce.org/uspstf/recommendation/ drug-use-illicit-primary-care-interventions-for-children-andadolescents

15. USPSTF. Unhealthy drug use: screening. Accessed April 30,
2021. https://uspreventiveservicestaskforce.org/uspstf/ recommendation/drug-use-illicit-screenin

16. USPSTF. Sexually transmitted infections: behavioral counseling Accessed April 30, 2021. https://uspreventiveservicestaskforce. org/uspstf/recommendation/sexually-transmitted-infectionsbehavioral-counseling.

17. Campos-Outcalt D. USPSTF update on sexually transmitted infections. J Fam Pract. 2020;69:514-517.

18. Brott TG, Halperin JL, Abbara S, et al; ASA/ACCF/AHA/AANN/ AANS/ACR/ASNR/CNS/SAIP/SCAI/SIR/SNIS/SVM/SVS guideline on the management of patients with extracranial carotid and vertebral artery disease. Catheter Cardiovasc Interv. 2013;81: E76-E123.

19. Ricotta JJ, Aburahma A, Ascher E, et al; Society for Vascular Surgery. Updated Society for Vascular Surgery guidelines for management of extracranial carotid disease. J Vasc Surg. 2011;54:e1-e31.

20. Farber HJ, Walley SC, Groner JA, et al; Section on Tobacco Control. Clinical practice policy to protect children from tobacco, nicotine, and tobacco smoke. Pediatrics. 2015;136:1008-1017.

\section{PRACTICE OPPORTUNITIES

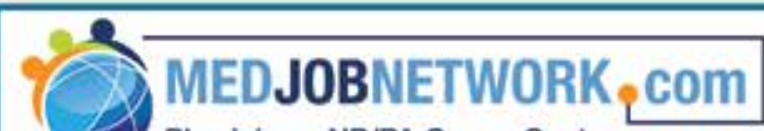 \\ Physician - NP/PA Career Center}

8 Please contact Tim LaPella to inquire about classified advertising in The Journal of Family Practice (circulation: 95,000$)$.

Display rates are available, with a discount for frequency. Per word rate for line ads is $\$ 5.25$. Phone 484-921-5001. Fax 484-921-5005.

E-mail: tlapella@mdedge.com. Visit our Web site at mdedge.com/familymedicine; visit MedJobNetwork.com.

\section{POSITIONS AVAILABLE}

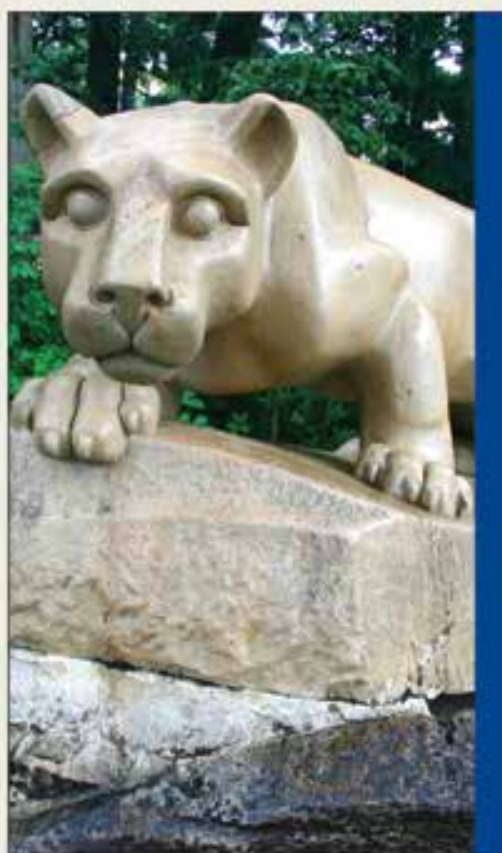

\section{Family Medicine Residency Core Faculty Physician}

Penn State Health St. Joseph Medical Center

Reading, PA

Penn State Health St. Joseph is seeking a BC/BE family medicine physician to join our team as a faculty member in our 6-6-6 Family and Community Medicine Residency Program in Berks County, PA. Priority will be given to candidates interested in inpatient medicine. The Family and Community Medicine Residency Program strives to provide excellent education in training family physicians to provide comprehensive, compassionate, coordinated and continuous high-quality patient-centered care to the community served by our Program.

Duties include teaching, mentoring, advising, and supervising residents; engaging in scholarly activity; and providing patient care. The residency program fosters a supportive family-oriented environment that encourages work-life balance.

Job Requirements

- Medical degree - M.D., D.0. or foreign equivalent

- Completion of an accredited Family Medicine residency program

- Board certification/eligibility in Family Medicine

- Experience in an academic setting preferred

- Conversational Spanish speaking skills preferred

\section{PennState Health}

TO APPLY, PLEASE SEND YOUR CURRICULUM VITAE (CV) TO:

Greg Emerick, MHA, CPRP - Physician Recruiter

Department of Human Resources - Penn State Health

E-mail: gemerick@pennstatehealth.psu.edu - Phone: 717-531-4725

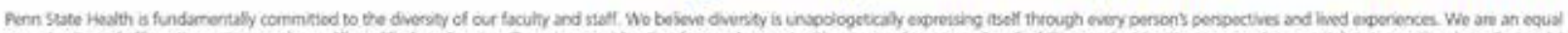

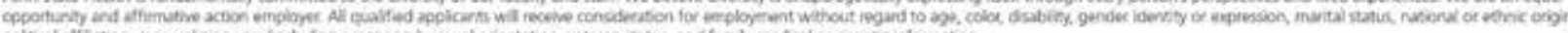

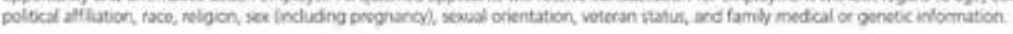

